\title{
Ten Years of Long-term Care Insurance in Korea: Light and Shade From a Geriatric Point of View
}

It is near ten years since the Korean national long-term care insurance (LTCI) system began in July, 20081). Senior citizens, who are 65 years or older, or citizens who are less than 65 years old but have chronic illnesses or disabilities, are eligible to apply. Among these, those who have difficulty in activities of daily living for a period of at least 6 months are considered eligible for LTCI. LTCI benefits include both in-kind and cash benefits. In-kind benefits consist of home care and institutional care services ${ }^{2}$. Initially, $\mathrm{LTCl}$ recipients were classified into 3 categories, with those in category 1 having the most severe disabilities; with the addition in July, 2014 of a new category, which indicates those with mild dementia, there are 5 categories at present ${ }^{3)}$. Consequently, the number of long-term care facilities increased from 1,754 in 2008 to 5,163 in 2016 and the number of care recipients also increased from 214,480 (4.2\% of the Korean citizens who are 65 years or older) in 2008 to 467,752 (7.0\%) in 2015,5).

According to the Long-term Care Insurance for the Aged $\mathrm{Act}^{6}{ }^{6}$, the aim of the $\mathrm{LTCl}$ is to provide assistance in physical or housekeeping activities for older people and eventually improving citizens' quality of life. However, most of the recipients eventually need medical services because their lack of normal function is usually due to severe chronic diseases ${ }^{5}$. Under the Elderly Welfare Law ${ }^{7}$, contracted physicians and nursing staff are required in nursing homes having 10 beds or more. However, physicians visit each resident only twice a month, and registered nurses account for less than a quarter of all nursing resources working at nursing homes ${ }^{1,5)}$. The Ministry of Health and Welfare revised the regulation for contracted physicians, requesting them to complete a three hour on-site education program to get certified by $2017^{1)}$. However, their medical practice is constrained and nursing staff can provide very limited medical services in nursing homes under the current medical law. So, it is essential that the severely ill residents of nursing homes are transferred to hospitals when they need medical treatment. However, the lack of an organized transition system between facilities and hospitals is the first big problem that has not been resolved yet. Second, small-scale facilities have increased exponentially. The number of facilities having 9 beds or less has increased from 422 in 2008 to 2,027 in 2016. In these facilities, contracted physicians are not required and most of them are owned and managed by private businesses, which results in the provision of low-quality services ${ }^{8)}$. Third, as the number of older citizens increases abruptly, higher insurance premiums and government funds are needed. In fact, LTCI registered a deficit of 40 billion won in 2016, the first time it had done so. Last, the periodic evaluation program for longterm care facilities is not focused on quality of services, but only on facilities ${ }^{8)}$.

Here are some suggestions for another decades of Korean LTCI system. First, establishment of a sound linking system between facilities and hospitals is needed for appropriate medical services for the recipients who are severely ill or disabled. Second, application of LTCl for long-term care hospitals including care workers should be considered. Third, reinforcement of long-term care evaluation system is necessary for quality improvement in each facility. Fourth, foundation of large-scale nonprofit institutions providing various services should be promoted by policy. Finally, training the contracted physicians to be able to manage old people in the long-term care environment will be of central importance.

Hyuk Ga

Editorial Board Member

Institute of Geriatric Medicine, Incheon Eun-Hye Hospital, Incheon, Korea E-mail: gahyuk@gmail.com

\section{REFERENCES}

1. Ga H. New system for Korean nursing home contracted physicians Began in 2017. Ann Geriatr Med Res 2017;21:35-6.

2. Ha JH. Health care policy for older Koreans. In: Federation of Korean Gerontological Societies. Ageing in Korea: today and tomorrow. 3rd ed. Seoul: Health Information Center; 2013. p. 130-9.

3. Lee MJ. Ten years of long-term care insurance: review and task of innovation [Internet]. Seoul: People's Solidarity for Participatory Democracy; c2016 [cited 2017 Nov 26]. Available from: http://www.peoplepower21.org/Welfare/1529437.

4. Korean Statistical Information Service. Tables of statistics [Inter- 
net]. Daejeon: Statistics Korea; [cited 2017 Feb 13]. Available from: http://kosis.kr/search/search.do.

5. Sunwoo D. Policy issues in elderly health and long-term care policy. Health Welf Policy Forum 2016;239:34-48.

6. Act on Long-Term Care Insurance for the Aged [Internet]. Sejong: Korea Ministry of Government Legislation; c1997-2017 [cited 2017 Nov 26]. Available from: http://www.law.go.kr/lsInfoP.do? lsiSeq=188085\&efYd=20170603\#0000.
7. Elderly Welfare Law [Internet]. Sejong: Korea Ministry of Government Legislation; c1997-2017 [cited 2017 Nov 26]. Available from: http://www.law.go.kr/lsInfoP.do?lsiSeq=178129\&efYd=20161 230\#0000.

8. Sunwoo D. Improvement direction of Long term care insurance system. In: Korean Society for Quality in Health Care. 2017 Congress of the Korean Society for Quality in Health Care. Seoul: Korean Society for Quality in Health Care; 2017. p. 108-30. 